\title{
Impact of pharmacological and psychological treatment methods of depressive and anxiety disorders on cognitive functioning
}

\author{
Krzysztof Krysta $\cdot$ Marek Krzystanek • \\ Małgorzata Janas-Kozik • Adam Klasik • \\ Irena Krupka-Matuszczyk
}

Received: 13 March 2014/ Accepted: 21 July 2014/Published online: 31 July 2014

(C) The Author(s) 2014. This article is published with open access at Springerlink.com

\begin{abstract}
Anxiety and depressive disorders are characterized by a number of clinical symptoms like decreased mood, apathy, anhedonia and anxiety. An important element of the clinical picture is also neurocognitive impairment. The most common treatment methods for depression and anxiety are pharmacology, psychotherapy or a combination of both methods. The data from literature show that those treatment methods lead to an improvement of clinical symptoms, but they exert a possible impact on cognitive functions. However the study results referring both to the role of pharmacological treatment and psychotherapy in this domain are still inconsistent. There is an increasing number of accessible data confirming the positive effects of those clinical interventions on cognitive functioning of anxiety and depressive patients, but the interpretation is complicated because of differences in methodology as well as examined sample size and their characteristics. More studies are then needed to describe this phenomenon.
\end{abstract}

Keywords Pharmacotherapy · Psychotherapy ·

Depression · Anxiety · Cognitive functions

K. Krysta $(\bowtie) \cdot$ M. Krzystanek · I. Krupka-Matuszczyk

Department of Psychiatry and Psychotherapy, Medical

University of Silesia, ul. Ziołowa 45/47,

60-635 Katowice, Poland

e-mail: krysta@mp.pl

M. Janas-Kozik

Department of Child and Adolescent Psychiatry and

Psychotherapy, Medical University of Silesia, ul. Zapolskiej 3,

41-218 Sosnowiec, Poland

A. Klasik

Institute of Psychology, University of Opole, Plac Staszica 1,

45-052 Opole, Poland

\section{Introduction}

Cognitive impairment is an important element of the clinical picture of psychiatric diseases which requires appropriate treatment and rehabilitation. According to neuropsychological literature it is defined as a decline in function in one or more domains of cognitive function. It may represent a single deficit which is highly specific or a cluster of deficits related to each other (Lezak et al. 2004). It is being discussed by experts, what should be the role of cognitive deficits in the diagnostic systems, and how they can discriminate such disorders like schizophrenia and affective disorders (Bora et al. 2010).

\section{Cognitive deficits in depression}

Traditional studies of unipolar depression and anxiety disorders focus on typical symptoms like decreased mood, apathy, anhedonia and anxiety but they do not pay sufficient attention to the cognitive functioning of the patients. Cognitive impairment may produce serious alteration in daily functioning. Cognitive deficits in major depressive disorder (MDD) in such domains as working memory, attention, and psychomotor processing speed are consistent, replicable, nonspecific, and clinically significant. They are regarded to be responsible for psychosocial impairment (McIntyre et al. 2013). Deficits in memory and decision-making are supposed to be present early in the course of the disease (Trivedi and Greer 2014). They are observed already in the first episode. Psychomotor speed and memory functioning are found to be associated with clinical state. Attention and deficits in executive functioning are regarded to be trait elements of MDD (Lee et al. 2012). In studies referring to euthymic depressive patients 
it was found that certain cognitive deficits like verbal memory, speed of information processing and some executive functions are persistent even during remissions (Bora et al. 2013). The study of Schaub et al. (2013) suggests that the most common deficits in this domain present in depressed patients relate to verbal and visual short-term memory, verbal fluency, visual-motor coordination, information processing in visual-verbal functioning and selective attention, however the results were not compared with healthy controls. Problems with attention and memory refer to the diagnostic criteria of depression and the patient's stopping to meet the criteria of depressive episode does not imply the cognitive symptoms to disappear. It was summarized by Roiser and Shakian (2013) that cognitive impairment non-related to emotional state is present in unipolar depression patients and that it tends to maintain even after the remission from a depressive episode. Moreover, the preserved cognitive impairment predicts poor response to the treatment with antidepressants. The relation between cognitive impairment in depression and the disease itself is not established. As reviewed by Goeldner et al. (2013), the cognitive deficit in depression seems incorporated in the body of depressive process, however in some subsets of the patients suffering from MDD, the intensity of cognitive impairment does not relate to the severity of depressive symptoms. The cognitive impairment is also present in patients who maintain residual symptoms of depression like fatigue, apathy and feeling a little low mood. The study of Pedrelli et al. (2010) showed that fatigue and feeling "blue" correlate with preservation of specific cognitive problems like difficulties in concentration and alertness. In the study of Gualtieri et al. (2006) the cognitive impairment, occurring during the depressive episode improved after the treatment with antidepressive drug but was not normalized. Apart from the concept of the two separated notions, different neuropsychlogical and some new neuroimagining studies (e.g. Pu et al. 2011) accumulate the evidence of the biological link between depression and the impairment of the cognition. One of the proposals, explaining problems in cognition among depressive patients is the depression-executive dysfunction (DED) model. According to DED model, the impairment of cognitive functioning, especially the executive functions, is likely to result in the poor response to antidepressants. However, due to the insufficient number of studies the hypothesis cannot be validated so far (McLennan and Mathias 2010).

Another issue raises from the biological treatment of depression. Antidepressants with alpha-adrenergic, anticholinergic and anti-histaminic activities or electro-convulsive therapy may cause significant cognitive impairment. However, the impact of medication appears to be mild and with doubtful clinical significance (Gorenstein et al. 2006). The problem is even more relevant for anxiety patients using benzodiazepines. The review done by Stewart (2005) showed that benzodiazepines produce cognitive dysfunctions in patients treated for longer periods and that the cognitive impairment may be preserved after the benzodiazepine withdrawal.

\section{Cognitive deficits in anxiety disorders}

Comparable deficits in this domain are present also in anxiety disorders (Hindmarch 1998). In anxiety disorders, it is proposed that cognitive impairment is a primary symptom, although it is well known that drugs, especially benzodiazepines interfere with cognition, too. The impact of anxiety on cognitive functioning is however less explored than in other disorders including depression (Jakuszkowiak-Wojten et al. 2013). Some early studies of this subject showed even no cognitive deficits in such conditions like panic disorder and social phobia (Gladsjo et al. 1998). However, according to other authors, reduced performance in panic disorder and social phobia patients, relative to control subjects, are found in the domains of verbal learning and memory (Asmundson et al. 1995). An intentional bias toward negatively-valenced verbal stimuli and longer decision-making latencies were observed by the authors of the study performed on subjects suffering from panic disorder (Kaplan et al. 2006). In another research project related to this group of patients, deficits in delayed visual memory and recognition test in CANTAB test were found (Raczak et al. 2013).

\section{Objective of the analysis}

There is an increasing number of data from literature showing that those cognitive deficits present in depressive and anxiety patients may decrease as a result of successful treatment. The objective of our analysis is to find out the impact of different pharmacological and psychological methods of treatment of depressive and anxiety disorders on the cognitive functioning in affected patients. The focus of this review was on studies on depression and anxiety disorders (1990-2014). We searched PubMed using the following search terms [effective date: 12th March 2014): (depression (Title/Abstract) OR anxiety (Title/Abstract)] AND pharmacotherapy (Title/Abstract) OR psychotherapy OR cognitive functions OR memory OR attention OR executive functions AND psychomotor speed AND English (lang) AND (1990/01/01(PDAT): 2014/03/12(PDAT)). 


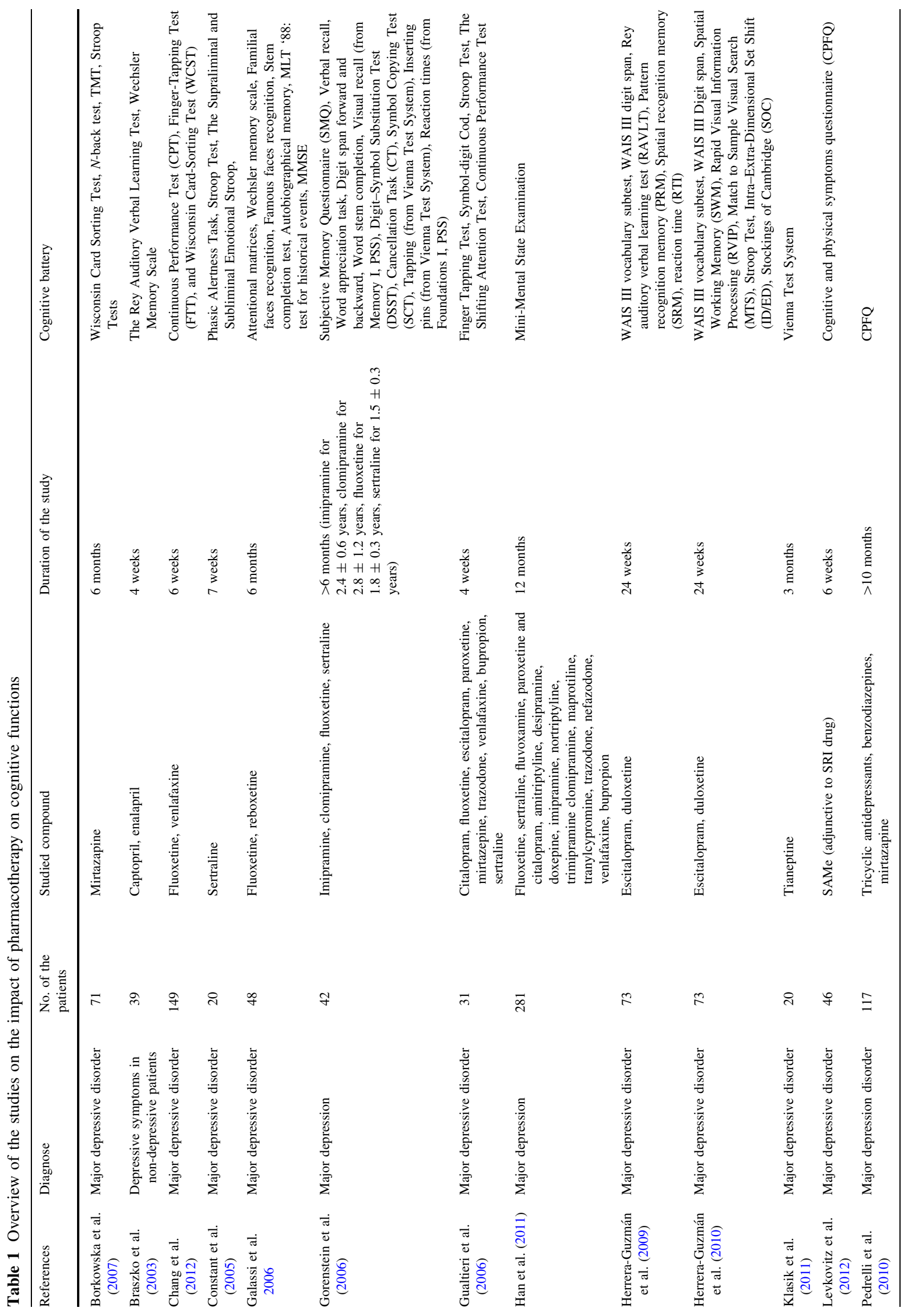




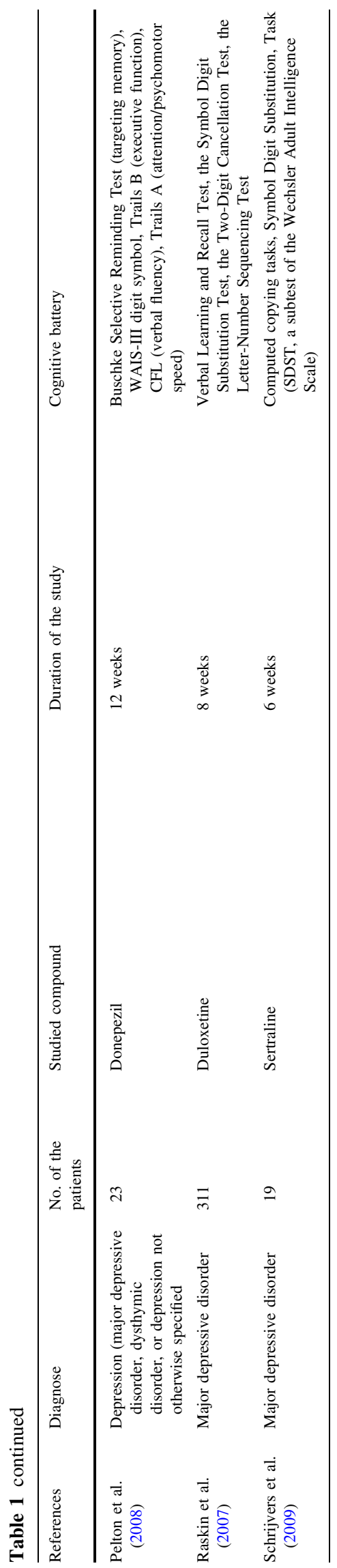

Impact of pharmacological treatment of depressive and anxiety disorders on cognition

The number of studies referring to the impact of pharmacological treatment of depressive and anxiety disorders on cognition is growing, however they still bring inconsistent results. Table 1 .

A relationship between the improvement of cognitive functioning as a result of antidepressant drugs was observed in a group of 50 patients treated with fluoxetine and reboxetine. Partial improvement in attention and memory was achieved, and no differences between patients treated with fluoxetine and reboxetine were found (Galassi et al. 2006). In other studies escitalopram and duloxetine improved the deficits of attention and executive functions (Herrera-Guzmán et al. 2010), as well as memory and mental processing speed (Herrera-Guzmán et al. 2009). Some reports confirm the positive impact of sertraline on cognition in patients with depressive and anxiety disorders (Constant et al. 2005; Schrijvers et al. 2009). In our own study we observed that a 3 -month treatment with tianeptine led to the improvement of attention and short-term memory in patients with mild and moderate depression (Klasik et al. 2011). On the other hand, in a 12-month study performed on a group of 281 old depressive patients aged 65 and older, antidepressant effect of citalopram, sertraline or paroxetine was not related to the improvement of cognitive symptoms (Han et al. 2011). Antidepressants were also found non-effective in the treatment of cognitive dysfunctions. The attempts to find any specific intervention to improve the cognitive symptoms in depression are promising. One of the agent is S-adenosyl methionine (SAMe). The naturally existing molecule may hypothetically modulate the neurotransmitter metabolism and improve the cognition in MDD (Krzystanek et al. 2011). In one of the recent studies, SAMe was added to the treatment with serotonin re-uptake inhibitor in $46 \mathrm{MDD}$ non-responders (Levkovitz et al. 2012). It was found that SAMe improves the ability to recall information in the studied group. Talarowska et al. (2012) examined the total antioxidant status (TAS) in depressive patients and she found that the higher the concentration of TAS in plasma of depressive patient is, the higher both the severity of depression and the impairment of short- and long-term declarative memory, working memory and verbal fluency are. Another study of 149 MDD patients revealed that cognitive performance, as well as treatment response in depressive patients, correlate with plasma CRP levels (Chang et al. 2012). Results of such studies may imply that anti-inflammatory drugs, as the adjunctive treatment, may play a role in preservation and/ or improvement of cognition in depressive patients. A similar example is the use of minocycline-neuroprotective and anti-inflammatory compound. It was reviewed by 
Pae et al. (2008) that minocycline may be effective for augmentation of antidepressants in the treatment of cognitive disfunctions in MDD. Another approach to identify the agents, producing specific improvement of cognition in depressive and anxiety patients is a use of sigma- 1 receptor agonist. From this point of view, very interesting is the attempt to use fluvoxamine, the potent sigma-1 receptor agonist. Fluvoxamine was proved in animal models and in human studies to improve the cognitive impairments (Hindmarch and Hashimoto 2010). Borkowska et al. (2007) reported the specific pro-cognitive effect of mirtazapine in improving cognitive impairment in unipolar depression. It is worth noticing that the improvement of cognition does not correlate with recovery from depressive symptoms and it occurred after 3 months of the mirtazapine treatment. After 6 months of the treatment, patients achieved the cognitive test results comparable with healthy controls. In one study also donepezil was found to improve the cognitive impairment in depressive patients aged 50 or more (Pelton et al. 2008). Donepezil in this study was added to the ongoing treatment with antidepressant. Raskin et al. (2007) studied the influence of duloxetine on cognitive deficits in MDD elderly patients. The study was done in considerable number of patients and revealed that duloxetine can significantly improve memory and verbal learning. Another small sample study with captopril and enalapril, angiotensin converting enzyme inhibitors, showed the antihypertensive drugs can improve cognition in nondepressive subjects (Braszko et al. 2003).

It is too early to draw any conclusions from the studies on the relation between the antidepressants and cognitive impairment in unipolar depression. Especially in anxiety disorders the studies are less than few and the field requires further exploration. Many more studies are necessary to establish the real impact of antidepressants on cognition, as well as to discriminate the negative influence of some antidepressants on cognition and to create new drug strategies for improvement of the cognitive impairment in depression and anxiety.

\section{Impact of psychological treatment methods of cognitive impairment in depression and anxiety disorders}

Except for pharmacology there is a number of non-biological interventions which may directly or indirectly lead to cognitive improvement in depressed patients. One group are interventions, whose primary goal is a cognitive training as a cognitive remediation. And the other group includes the traditional methods of psychotherapy, like psychodynamic psychotherapy, CBT, interpersonal psychotherapy, for which the main goal is the improvement of patient's clinical symptoms. The impact on neurocognition may be an additional value of the therapeutic interventions.

\section{Role of cognitive training methods}

The usefulness of the cognitive remediation was confirmed in a number of studies. Elgamal et al. (2007) observed a positive impact of cognitive training on attention, verbal learning and memory, psychomotor speed and executive function in recurrent major depressive disorder. Naismith et al. (2010) observed improvement in memory performance in patients with affective disorders. Bowie et al. (2013a) confirmed a positive impact of daily online cognitive exercises on such domains like attention/processing speed and verbal memory in patients with treatmentresistant depression. The authors of the above study analyze and emphasize the advantages on cognitive remediation trainings in mood disorders in their review (Bowie et al. 2013b).

\section{Neuroimaging studies evidence of the psychotherapy effectiveness in cognitive improvement}

\section{Depressive disorders}

In literature we can find an increasing number of studies analyzing the neurobiological basis of psychotherapy (de Vries et al. 2013), however the research data are still not consistent and valuable, as the number of studies is still small and they differ in methodology and evaluated treatment strategies (Karch et al. 2012). Some of the adopted methods of analyzing the impact of psychotherapy on brain functioning are neuroimaging techniques. Modulation of limbic and cortical regions was observed in patients with unipolar depression treated with CBT (Goldapple et al. 2004). In some studies certain differences in the effect of both treatment methods are reported. The study comparing the results of the treatment with CBT and venlafaxine in a group of patients with major depressive disorder, revealed that CBT modulates cortical-limbic connectivity and that venlafaxine engages additional cortical and striatal regions (Kennedy et al. 2007).

\section{Anxiety disorders}

It was found that cognitive-behavioral therapy of panic disorder reduces the hyperactivity in several brain areas causing adaptive metabolic changes of the medial prefrontal cortex (Sakai et al. 2006). Similar changes were found after the treatment either with CBT or with antidepressants in patients 
Table 2 Overview of the studies on the impact of psychotherapy on cognitive functions

\begin{tabular}{|c|c|c|c|c|c|c|}
\hline & Diagnose & $\begin{array}{l}\text { No. of } \\
\text { patients }\end{array}$ & $\begin{array}{l}\text { Duration } \\
\text { of the } \\
\text { study }\end{array}$ & Cognitive battery & $\begin{array}{l}\text { Model of } \\
\text { psychotherapy }\end{array}$ & $\begin{array}{l}\text { Additional } \\
\text { pharmacotherapy }\end{array}$ \\
\hline $\begin{array}{l}\text { Klasik } \\
\text { et al. } \\
(2012)\end{array}$ & $\begin{array}{l}\text { Recurrent Depressive } \\
\text { Disorder }\end{array}$ & 60 & 8 weeks & Vienna Test System (VTS) & Psychodynamic & $\begin{array}{r}\text { Sertraline (in } 2 \text { of } 3 \\
\text { examined groups) }\end{array}$ \\
\hline $\begin{array}{l}\text { Bastos } \\
\text { et al. } \\
\text { (2013) }\end{array}$ & Moderate depression & 272 & 2 years & WAIS-III & Psychodynamic & $\begin{array}{l}\text { Fluoxetine (in } 2 \text { of } 3 \\
\text { examined groups) }\end{array}$ \\
\hline $\begin{array}{l}\text { Reinecke } \\
\text { et al. } \\
\text { (2013) }\end{array}$ & Panic disorder & 28 & 4 weeks & Attention visual probe task & CBT & $\begin{array}{l}\text { Exclusion criterion: } \\
\text { psychopharmacological } \\
\text { treatment during the last } \\
6 \text { months }\end{array}$ \\
\hline $\begin{array}{l}\text { Dobkin } \\
\text { et al. } \\
(2014)\end{array}$ & $\begin{array}{l}\text { Major Depressive } \\
\text { Disorder (MDD), } \\
\text { Dysthymia, or } \\
\text { Depression Not } \\
\text { Otherwise Specified, } \\
\text { Parkinson's disease }\end{array}$ & 80 & 10 weeks & $\begin{array}{l}\text { Hopkins Verbal Learning Test- } \\
\text { Revised (HVLT-R), Delis- } \\
\text { Kaplan Executive Function } \\
\text { System (D-KEFS), Wechsler } \\
\text { Memory Scales, Stroop Color } \\
\text { and Word Test }\end{array}$ & CBT & $\begin{array}{l}\text { Stable medication } \\
\text { regimen for } \geq 6 \text { weeks }\end{array}$ \\
\hline $\begin{array}{c}\text { Mackin } \\
\text { et al. } \\
2013\end{array}$ & Late life depression & 221 & 24 weeks & $\begin{array}{l}\text { Stroop Color and Word Test, } \\
\text { Hopkins Verbal Learning Test - } \\
\text { Revised (HVLT-R), DRS-IP, } \\
\text { Wisconsin Card Sorting Test-64 } \\
\text { Computer Version, Trail } \\
\text { Making Test (TMT) }\end{array}$ & $\begin{array}{l}\text { Problem } \\
\text { Solving } \\
\text { Therapy, } \\
\text { Supportive } \\
\text { Therapy }\end{array}$ & $\begin{array}{l}\text { Antidepressant-free } \\
\text { participants }\end{array}$ \\
\hline
\end{tabular}

suffering from panic disorder (Prasko et al. 2004) or from social phobia (Furmark et al. 2002).

Importance of methodological limitations

The field of neuroimaging studies confirming the effects of psychotherapy on modulation of functioning on different structures of the brain is still growing, bringing more and more findings (Lindauer et al. 2008; Buchheim et al. 2012; Cervenka et al. 2012; Gawrysiak et al. 2013; Goldin et al. 2013; Morgiève et al. 2013; Schiepek et al. 2013) Recent advances in this filed were reviewed by Barsaglini et al. 2013. The authors conclude that the impact of psychotherapy on measurable changes in the brain is beyond doubt, but it appears to be dependent on the investigated disorder and the type of the therapy used. Messina et al. (2013) in their meta-analysis also confirm positive neural changes in brain networks associated to emotion regulation after psychotherapy of depression and anxiety drawing the attention to methodological limitations like small sizes, lack of suitable control groups, heterogeneity of techniques or study designs.

Neuropsychological studies evidence of the beneficial effect of psychotherapy on cognition

Contrary to the results of neuroimaging studies, the access to research data related to the neuropsychological evaluation of cognitive changes occurring in the process of psychotherapy is very limited. This also refers to studies comparing the cognitive functioning in patients treated with psychotherapy and pharmacotherapy. Table 2 .

In a recent study performed in Brasil 272 patients aged 26-34 were examined. They were randomly divided in three subgroups. The first subgroup was treated with long-term psychodynamic psychotherapy, the second with fluoxetine, and the third received both psychotherapeutic and pharmacological treatment. The intensity of depression was evaluated with the use of Beck Depression Inventory (BDI), and the neurocognitive deficits assessed with the Wechsler adult intelligence scale, third edition (WAIS-III). The study lasted 2 years, and the neuropsychological examination was repeated every six months. Patients treated with the combination of psychodynamic psychotherapy and fluoxetine presented the greatest improvement in cognitive scores at the end of the study. The lowest improvement was observed in the group of patients treated with fluoxetine (Bastos et al. 2013). The results of this study were similar to our own. However, the number of patients participating in our research project was smaller, we recruited 60 patients with a diagnosis of recurrent depressive disorder. They were also divided into three subgroups treated with pharmacotherapy with sertraline, psychodynamic psychotherapy or both. The neuropsychological changes occurring during 
the treatment process were assessed with the Vienna Test System (VTS). In comparison to the Brasilian study, the time of observation was much shorter ( 8 weeks). The improvement in short-term memory and attention was also the most prominent in patients treated with both forms of therapy. However, contrary to the results of the Brasilian study, the worst performing group consisted of patients was treated with psychotherapy alone (Klasik et al. 2012). What is the mechanism of information processing during the psychodynamic therapeutic process, still remains unclear. Novac (2013) proposed the use of a term "transprocessing" illustrating the discussed phenomena. This term is a combination of two terms. The first term is transduction, which is reexpression and translation of a functional brain activity into a new type activity, like transduction of stress in the function of the hypothalamopituitary axis. The second term is processing, a function by which the brain makes sense of environmental inputs. According to the author, changes in these processes during psychotherapy are internalized and assimilated. A small number of studies analyze the influence of Cognitive-Behavioral Therapy (CBT) on neurocognition. Reinecke et al. (2013) performed a study on a group of 28 patients with panic disorder. Attention visual probe task was performed a day after the treatment session and 4 weeks later. The authors observed the decrease of vigilance for threat information in the treated group, and the magnitude of this early effect predicted therapeutic response. There is also evidence from literature that psychotherapy may improve neurocognition in depressive disorders related to a psychoorganic condition. Mackin et al. (2013) observed a beneficial effect of psychotherapy on cognitive functioning after psychotherapy treatment of depression in older adults with executive dysfunction. Dobkin et al. (2014) described a neuropsychological improvement in patients with Parkinson's disease after cognitive-behavioral treatment of depression. Improvements in verbal memory and executive functioning were observed after 10-week treatment period. Collerton (2013) proposed the explanation of possible structural and functional brain changes after CBT psychotherapy treatment related to neuroplasticity in the linked systems of the frontal, cingulate, and limbic cortex. Except from the theories aiming at the explanation of psychotherapy effects, efforts are also made to analyze the interaction of combined pharmacological and psychological interventions. An interesting approach was presented by Castrén (2013), proposing a hypothesis that antidepressant agents reactivate juvenile-like plasticity in the cortex, which facilitates further recovery of neuronal networks related to psychotherapy and other non-pharmacological interventions in mood disorders.

\section{Conclusions}

Deficits in neurocognition play a significant role among other symptoms of depressive and anxiety disorders. It is important for the clinicians to what extent the commonly used methods of treatment of these conditions exert a positive influence on cognitive processes. The results of studies using pharmacological treatment are inconsistent. There is a group of research findings suggesting a favorable effect of antidepressive treatment on this domain of symptoms (Galassi et al. 2006; Borkowska et al. (2007); Herrera-Guzmán et al. 2009, 2010; Klasik et al. 2011). Other data from literature suggest no cognitive improvement following treatment of antidepressants (Han et al. 2011). Efforts are made to introduce other types of pharmacotherapy in order to reach the expected goal, like the use of donepezil (Pelton et al. 2008) or captopril and enalapril (Braszko et al. 2003), S-adenosyl methionine (SAMe) (Krzystanek et al. 2011; Levkovitz et al. 2012). Anyway, the studies on the impact of antidepressant medication on cognitive functioning in depression and anxiety patients are still insufficient in number and they do not allow to come to any final conclusion about its effectiveness towards the cognitive impairment in depression. On the other hand, an increasing interest of the researches is focused on the impact of non-biological treatment methods on this domain of symptoms. This interest is enhanced by a growing data from neuroimaging studies confirming the impact of functional changes in brain structures following psychotherapeutic process (Barsaglini et al. 2013; Messina et al. 2013). Some reports confirm the positive effect of different psychotherapeutic treatment methods on the improvement of cognitive skills alongside with clinical improvement (Klasik et al. 2012; Bastos et al. 2013; Reinecke et al. 2013; Dobkin et al. 2014). The above studies are small in number and do not allow to draw unequivocal conclusions. What is however suggested by research study results in this field, psychotherapy and pharmacotherapy used in combination may be more effective than each of those methods used alone (Klasik et al. 2012; Bastos et al. 2013, Castrén 2013).

The above analysis suggests that the commonly used pharmacological and non-pharmacological treatment strategies targeted to help patients suffering from depressive and anxiety disorders may have a positive influence non only on clinical symptoms of those conditions, but also on patients' cognitive functioning. Because of a relatively small number of studies and different methodological attitudes, we still need to continue our research in order to explain discussed phenomenon more profoundly. Except for the widely used treatment methods like pharmacotherapy and psychotherapy, additional techniques of cognitive 
enhancement should be used in the treatment process, both biological, like e.g. transcranial magnetic stimulation techniques (Balconi 2013), and non-biological, like cognitive training (Elgamal et al. 2007; Naismith et al. 2010; Bowie et al. 2013a).

Conflict of interest The authors have no disclosures to declare.

Open Access This article is distributed under the terms of the Creative Commons Attribution License which permits any use, distribution, and reproduction in any medium, provided the original author(s) and the source are credited.

\section{References}

Asmundson GJG, Stein MB, Larsen DK, Walker JR (1995) Neurocognitive function in panic disorder and social phobia patients. Anxiety 1:201-207

Balconi M (2013) Dorsolateral prefrontal cortex, working memory and episodic memory processes: insight through transcranial magnetic stimulation techniques. Neurosci Bull 29:381-389

Barsaglini A, Sartori G, Benetti S, Pettersson-Yeo W, Mechelli A (2013) The effects of psychotherapy on brain function: A systematic and critical review. Prog Neurobiol. doi:10.1016/j. pneurobio.2013.10.006

Bastos AG, Guimarães LS, Trentini CM (2013) Neurocognitive changes in depressed patients in psychodynamic psychotherapy, therapy with fluoxetine and combination therapy. J Affect Disord 151:1066-1075

Bora E, Yücel M, Pantelis C (2010) Cognitive impairment in schizophrenia and affective psychoses: implications for DSM-V criteria and beyond. Schizophr Bull 36:36-42

Bora E, Harrison BJ, Yücel M, Pantelis C (2013) Cognitive impairment in euthymic major depressive disorder: a metaanalysis. Psychol Med 43:2017-2026

Borkowska A, Drozdz W, Ziółkowska-Kochan M, Rybakowski J (2007) Enhancing effect of mirtazapine on cognitive functions associated with prefrontal cortex in patients with recurrent depression. Neuropsychopharmacol Hung 9:131-136

Bowie CR, Gupta M, Holshausen K, Jokic R, Best M, Milev R (2013a) Cognitive remediation for treatment-resistant depression: effects on cognition and functioning and the role of online homework. J Nerv Ment Dis 201:680-685

Bowie CR, Gupta M, Holshausen K (2013b) Cognitive remediation therapy for mood disorders: rationale, early evidence, and future directions. Can J Psychiatr 58:319-325

Braszko JJ, Karwowska-Polecka W, Halicka D, Gard PR (2003) Captopril and enalapril improve cognition and depressed mood in hypertensive patients. J Basic Clin Physiol Pharmacol 14:323-343

Buchheim A, Viviani R, Kessler H, Kächele H, Cierpka M, Roth G, George C, Kernberg OF, Bruns G, Taubner S (2012) Changes in prefrontal-limbic function in major depression after 15 months of long-term psychotherapy. PLoS One 7:e33745

Castrén E (2013) Neuronal network plasticity and recovery from depression. JAMA Psychiatr 70:983-989

Cervenka S, Hedman E, Ikoma Y, Djurfeldt DR, Rück C, Halldin C, Lindefors N (2012) Changes in dopamine D2-receptor binding are associated to symptom reduction after psychotherapy in social anxiety disorder. Transl Psychiatr 22(2):e120

Chang HH, Lee IH, Gean PW, Lee SY, Chi MH, Yang YK, Lu RB, Chen PS (2012) Treatment response and cognitive impairment in major depression: association with C-reactive protein. Brain Behav Immun 26:90-95

Collerton D (2013) Psychotherapy and brain plasticity. Front Psychol 4:548

Constant EL, Adam S, Gillain B, Seron X, Bruyer R, Seghers A (2005) Effects of sertraline on depressive symptoms and attentional and executive functions in major depression. Depress Anxiety 21:78-89

de Vries U, Schüßler G, Petermann F (2013) The neuropsychological principles of psychotherapy. Z Psychosom Med Psychother 59:301-310

Dobkin RD, Tröster AI, Rubino JT, Allen LA, Gara MA, Mark MH, Menza M (2014) Neuropsychological outcomes after psychosocial intervention for depression in Parkinson's Disease. J Neuropsychiatr Clin Neurosci 26:57-63

Elgamal S, McKinnon MC, Ramakrishnan K, Joffe RT, MacQueen G (2007) Successful computer-assisted cognitive remediation therapy in patients with unipolar depression: a proof of principle study. Psychol Med 37:1229-1238

Furmark T, Tillfors M, Marteinsdottir I, Fischer H, Pissiota A, Långström B, Fredrikson M (2002) Common changes in cerebral blood flow in patients with social phobia treated with citalopram or cognitive-behavioral therapy. Arch Gen Psychiatr 59:425-433

Galassi R, Di Sarro R, Morreale A, Amore M (2006) Memory impairment in patients with late-onset major depression: the effect of antidepressant therapy. J Affect Disord 91:243-250

Gawrysiak MJ, Swan SA, Nicholas CR, Rogers BP, Dougherty JH, Hopko DR (2013) Pragmatic psychodynamic psychotherapy for a patient with depression and breast cancer: functional MRI evaluation of treatment effects. Am J Psychother 67:237-255

Gladsjo JA, Rapaport MH, McKinney R, Lucas JA, Rabin A, Oliver T, Davis J, Auerbach M, Judd LL (1998) A neuropsychological study of panic disorder: negative findings. J Affect Disord 49:123-131

Goeldner C, Ballard TM, Knoflach F, Wichmann J, Gatti S, Umbricht D (2013) Cognitive impairment in major depression and the mGlu2 receptor as a therapeutic target. Neuropharmacology 64:337-346

Goldapple K, Segal Z, Garson C, Lau M, Bieling P, Kennedy S, Mayberg H (2004) Modulation of cortical-limbic pathways in major depression: treatment-specific effects of cognitive behavior therapy. Arch Gen Psychiatr 61:34-41

Goldin PR, Ziv M, Jazaieri H, Hahn K, Heimberg R, Gross JJ (2013) Impact of cognitive behavioral therapy for social anxiety disorder on the neural dynamics of cognitive reappraisal of negative self-beliefs: randomized clinical trial. JAMA Psychiatr 70:1048-1056

Gorenstein C, de Carvalho SC, Artes R, Moreno RA, Marcourakis T (2006) Cognitive performance in depressed patients after chronic use of antidepressants. Psychopharmacology 185:84-92

Gualtieri CT, Johnson LG, Benedict KB (2006) Neurocognition in depression: patients on and off medication versus healthy comparison subjects. J Neuropsychiatry Clin Neurosci $18: 217-225$

Han L, McCusker J, Cole M, Capek R, Abrahamowicz M (2011) Antidepressant use and cognitive functioning in older medical patients with major or minor depression: a prospective cohort study with database linkage. J Clin Psychopharmacol 31:429-435

Herrera-Guzmán I, Gudayol-Ferré E, Herrera-Guzmán D, GuàrdiaOlmos J, Hinojosa-Calvo E, Herrera-Abarca JE (2009) Effects of selective serotonin reuptake and dual serotonergic-noradrenergic reuptake treatments on memory and mental processing speed in patients with major depressive disorder. J Psychiatr Res 43:855-863

Herrera-Guzmán I, Herrera-Abarca JE, Gudayol-Ferré E, HerreraGuzmán D, Gómez-Carbajal L, Peña-Olvira M, Villuendas- 
González E, Joan GO (2010) Effects of selective serotonin reuptake and dual serotonergic-noradrenergic reuptake treatments on attention and executive functions in patients with major depressive disorder. Psychiatr Res 177:323-329

Hindmarch I (1998) Cognition and anxiety: the cognitive effects of anti-anxiety medication. Acta Psychiatr Scand Suppl 393:89-94

Hindmarch I, Hashimoto K (2010) Cognition and depression: the effects of fluvoxamine, a sigma-1 receptor agonist, reconsidered. Hum Psychopharmacol 25:193-200

Jakuszkowiak-Wojten K, Gałuszko-Węgielnik M, Raczak A, Cubała WJ, Wiglusz MS, Herstowska M, Landowski J (2013) Impulsivity in panic disorder: neuropsychological correlates. Psychiatr Danub 25(Suppl 2):S149-S152

Kaneko K, Nakagome K (2011) A multi-channel near-infrared spectroscopy study of prefrontal cortex activation during working memory task in major depressive disorder. Neurosci Res 70:91-97

Kaplan JS, Erickson K, Luckenbaugh DA, Weiland-Fiedler P, Geraci M, Sahakian BJ, Charney D, Drevets WC, Neumeister A (2006) Differential performance on tasks of affective processing and decision-making in patients with panic disorder and panic disorder with comorbid major depressive disorder. J Affect Disord 95:165-171

Karch S, Heinzel S, Pogarell O, Schiepek G (2012) Neurobiological basis of psychotherapeutic approaches. Methodological demands and results for psychiatric disorder patterns. Psychotherapeut 57:204-212

Kennedy SH, Konarski JZ, Segal ZV, Lau MA, Bieling PJ, McIntyre RS, Mayberg HS (2007) Differences in brain glucose metabolism between responders to CBT and venlafaxine in a 16-week randomized controlled trial. Am J Psychiatr 164:778-788

Klasik A, Krysta K, Krupka-Matuszczyk I (2011) Effect of tianeptine on cognitive functions in patients with depressive disorders during a 3-month observation. Psychiatr Danub 23(Suppl 1):S18-S22

Klasik A, Krysta K, Krzystanek M (2012) Impact of psychotherapy and antidepressive treatment on cognitive functions in patients treated for depression. Psychiatr Danub 24(Suppl 1):S130-S134

Krzystanek M, Pałasz A, Krzystanek E, Krupka-Matuszczyk I, Wiaderkiewicz R, Skowronek R (2011) S-adenosyl L-methionine in CNS diseases. Psychiatr Pol 45:923-931

Lee RS, Hermens DF, Porter MA, Redoblado-Hodge MA (2012) A meta-analysis of cognitive deficits in first-episode major depressive disorder. J Affect Disord 140:113-124

Levkovitz Y, Alpert JE, Brintz CE, Mischoulon D, Papakostas GI (2012) Effects of S-adenosylmethionine augmentation of serotonin-reuptake inhibitor antidepressants on cognitive symptoms of major depressive disorder. J Affect Disord 136:1174-1178

Lezak MD, Howieson DB, Loring DW (2004) Neuropsychological Assessment. Oxford University Press

Lindauer RJ, Booij J, Habraken JB, van Meijel EP, Uylings HB, Olff M, Carlier IV, den Heeten GJ, van Eck-Smit BL, Gersons BP (2008) Effects of psychotherapy on regional cerebral blood flow during trauma imagery in patients with post-traumatic stress disorder: a randomized clinical trial. Psychol Med 38:543-554

Mackin RS, Nelson JC, Delucchi K, Raue P, Byers A, Barnes D, Satre DD, Yaffe K, Alexopoulos GS, Arean PA (2013) Cognitive outcomes after psychotherapeutic interventions for major depression in older adults with executive dysfunction. Am J Geriatr Psychiatr. doi:10.1016/j.jagp.2013.11.002

McIntyre RS, Cha DS, Soczynska JK, Woldeyohannes HO, Gallaugher LA, Kudlow P, Alsuwaidan M, Baskaran A (2013) Cognitive deficits and functional outcomes in major depressive disorder: determinants, substrates, and treatment interventions. Depress Anxiety 30:515-527
McLennan SN, Mathias JL (2010) The depression-executive dysfunction (DED) syndrome and response to antidepressants: a meta-analytic review. Int J Geriatr Psychiatr 25:933-944

Messina I, Sambin M, Palmieri A, Viviani R (2013) Neural correlates of psychotherapy in anxiety and depression: a meta-analysis. PLoS One 8(9):e74657

Morgiève M, N'diaye K, Haynes WI, Granger B, Clair AH, Pelissolo A, Mallet L (2013) Dynamics of psychotherapy-related cerebral haemodynamic changes in obsessive compulsive disorder using a personalized exposure task in functional magnetic resonance imaging. Psychol Med 4:1-13

Naismith SL, Redoblado-Hodge MA, Lewis SJ, Scott EM, Hickie IB (2010) Cognitive training in affective disorders improves memory: a preliminary study using the NEAR approach. J Affect Disord 121:258-262

Novac A, Bota RG (2013) Transprocessing: neurobiologic mechanisms of change during psychotherapy-a proposal based on a case report. Perm J. doi:10.7812/TPP/12-045

Pae CU, Marks DM, Han C, Patkar AA (2008) Does minocycline have antidepressant effect? Biomed Pharmacother 62:308-311

Pedrelli P, Baer L, Losifescu DV, Fava M (2010) Relationship between residual symptoms of depression and self-reported cognitive impairment. CNS Spectr 15:46-51

Pelton GH, Harper OL, Tabert MH, Sackeim HA, Scarmeas N, Roose SP, Devanand DP (2008) Randomized double-blind placebocontrolled donepezil augmentation in antidepressant-treated elderly patients with depression and cognitive impairment: a pilot study. Int J Geriatr Psychiatr 23:670-676

Prasko J, Horácek J, Záleský R, Kopecek M, Novák T, Pasková B, Skrdlantová L, Belohlávek O, Höschl C (2004) The change of regional brain metabolism (18FDG PET) in panic disorder during the treatment with cognitive behavioral therapy or antidepressants. Neuro Endocrinol Lett 25:340-348

Pu S, Yamada T, Yokoyama K, Matsumura H, Kobayashi H, Sasaki N, Mitani H, Adachi A, Kaneko K, Nakagome K (2011) A multichannel near-infrared spectroscopy study of prefrontal cortex activation during working memory task in major depressive disorder. Neurosci Res 70:91-97

Raczak A, Jakuszkowiak-Wojten K, Gałuszko-Węgielnik M, Cubała WJ, Wiglusz MS, Herstowska M, Landowski J (2013) Immediate and delayed visual memory and recognition in patients with panic disorders. Psychiatr Danub 25(Suppl 2):S146-S148

Raskin J, Wiltse CG, Siegal A, Sheikh J, Xu J, Dinkel JJ, Rotz BT, Mohs RC (2007) Efficacy of duloxetine on cognition, depression, and pain in elderly patients with major depressive disorder: an 8-week, double-blind, placebo-controlled trial. Am J Psychiatr 164:900-909

Reinecke A, Waldenmaier L, Cooper MJ, Harmer CJ (2013) Changes in automatic threat processing precede and predict clinical changes with exposure-based cognitive-behavior therapy for panic disorder. Biol Psychiatr 73:1064-1070

Roiser JP, Sahakian BJ (2013) Hot and cold cognition in depression. CNS Spectr 18:139-149

Sakai Y, Kumano H, Nishikawa M, Sakano Y, Kaiya H, Imabayashi E, Ohnishi T, Matsuda H, Yasuda A, Sato A, Diksic M, Kuboki $\mathrm{T}$ (2006) Changes in cerebral glucose utilization in patients with panic disorder treated with cognitive-behavioral therapy. Neuroimage 33:218-226

Schaub A, Neubauer N, Mueser KT, Engel R, Möller HJ (2013) Neuropsychological functioning in inpatients with major depression or schizophrenia. BMC Psychiatr 13:203

Schiepek G, Tominschek I, Heinzel S, Aigner M, Dold M, Unger A, Lenz G, Windischberger C, Moser E, Plöderl M, Lutz J, Meindl T, Zaudig M, Pogarell O, Karch S (2013) Discontinuous patterns of brain activation in the psychotherapy process of obsessive- 
compulsive disorder: converging results from repeated FMRI and daily self-reports. PLoS One 8:e71863

Schrijvers D, Maas YJ, Pier MP, Madani Y, Hulstijn W, Sabbe BG (2009) Psychomotor changes in major depressive disorder during sertraline treatment. Neuropsychobiology 59:34-42

Stewart SA (2005) The effects of benzodiazepines on cognition. J Clin Psychiatr 66 Suppl 2:13-19

Talarowska M, Gałecki P, Maes M, Bobińska K, Kowalczyk E (2012)

Total antioxidant status correlates with cognitive impairment in patients with recurrent depressive disorder. Neurochem Res 37:1761-1767

Trivedi MH, Greer TL (2014) Cognitive dysfunction in unipolar depression: implications for treatment. J Affect Disord 152-154:19-27 